D E R E C H O $\mathrm{R}$ U R A L

\title{
El Régimen Legal de Tierras de Montaña
}

\author{
(Apuntes) \\ por el DR. LUIS GAZZOLO. \\ Catedrático de las Facultades de Derecho \\ de las Universidades Católica y de San Marcos.
}

El Estado en su deseo de incorporar nuestra selva a la actividad productiva del país, ha tratado de reglamentar las concesiones y adjudicaciones de Terrenos de Montaña.

Antes de la Ley $\mathrm{N}^{\circ} 1220$ de 1909, que casi tiene cincuenta años de existencia, existieron antecedentes legislativos cristalizados en una serie de leyes, Decretos Supremos y. Resoluciones, con el objeto de conceder terrenos de montaña en Amazonas, Chanchamayo y Loreto, de poblarlos y colonizarlos; tal como la Ley de Inmigración y colonización del 14 de Octubre de 1893.

Pero todas estas leyes fueron cristalizaciones aisladas sin ningún nexo orgánico, hasta que apareció la primera Ley Orgánica de Terrenos de Montaña del 21 de Diciembre de 1898, en época del gobierno de Don Nicolás de Piérola.

\section{Ley del 21 de Diciembre de 1898}

Según esta ley, las tierras que no hayan sido adquiridas por los particulares, son de propiedad del Estado. túan:

Los modos de adquisición de dominio por los particulares se efec-
a.-por compra;
b. - por concesión;
c.-por adjudicación gratuita $Y$
d.-por contrato de colonización.

La compra daba absoluto y perpétuo dominio sobre las tierras adquiridas; el precio era de cinco soles por hectúrec. 
Por concesión, abonando un canon anual de un sol por Ha. en los tres primeros años e igual suma en lo sucesivo por la parte cultivada, y el doble decir dos soles por Ha. no cultivada. El que deje de pagar el canon al vencimiento de dos años, pierde todo derecho de posesión y propiedad, volviendo las tlerras a dominio del Estado.

Por adjudicación gratuita.-Siempre que no pase dos Has.; si el adjudicatario no cultiva dentro del plazo de tres años la mitad del terreno, perderá todo derecho sobre él, a no ser que se someta al pago del canon que se establece en el art. 4 de la ley.

Por contrato de colonización.-Dando cumplimiento a las estipula. ciones acordadas en cada caso.-Los contratos de colonización deben hacerse con garantía efectiva de cumplimiento, equivalente al valor de las tierras cedidas a razón de cinco soles por hectárea.

Procedimiento para la adquisición: se solicitaba hasta 18 Has. a los sub prefectos; 120 Has. a los Prefectos, 1200 Has. al Gobiemo y mayor número al Congreso.

\section{LEGISLACION VIGENTE}

La legislación que rige en la materia se concreta en la Ley $N^{\circ} 1220$ del 31 de Diciembre de 1909 y su respectivo Reglamento del 11 de Marzo do 1910.

También es necesario mencionar los Decretos Supremos y leyes que fomentan la colonización de la Montcña, tales como los centros de Colonización oficiales de Tingo María, Santa Clotilde, Satipo, Pangoa, Tambopata y Marcapata.

LA LEY GENERAL DE TIERRÁS DE MONTÃ̃̃A.-Es del 31 de Diciembre de 1909.-En el art. $1^{\circ}$ de la ley se explica qué se entiende por tierras de Montaña, al considerar con este carácter a las que están situadas en la zona fluvial de la República $Y$ constituyen la región de los bosques; sin embargo el reglamento de esta ley precisa aún más el concepto, al establecer que se entiende por zorá fluvial: el territorio regado por los ríos que directamente o indirectamente van a engrosar las aguas del Amazonas (Art. 29 del Reglamento de la Ley de Tierras de Montaña).

Por principio las tierras de Montaña son de dominio público y se pueden conceder a los particulares para su explotación y aprovechamiento. Sin embargo hay tierras que no pueden ser concedidas, tales como las zonas que se reserva el gobierno a fin de estudiar y determinar su más conveniente aplicación (Ârt. 20 de la Ley 1220) y lạs que se encuentran situadas en las fronteras, que están sujetas a autorización especialísima.

Excepciones:-Las concesiones que se otorguen por la Ley de Montaña no podrán comprender en ningún caso:

1.-Los terrenos situados dentro de las poblaciones exiștentegs, hasta dos kilómetros a la redonda de su plaza principal.

2.-Los terrenos situados en las márgenes de los rios y lagos en una extensión de cincuenta metros, a partir de la línea que marca su lecho nor- 
mal en los ríos inundables; $\mathrm{y}$ hasta veinte metros de sus más salientes sinuosidades en los no inundables.

3.-Los terrenos que fuesen necesarios para caminos o edificios públicos los que se emplearán en tales objetos, sin sujetarse a los trómites comunes a la expropiación y dando en este caso a los propietarios otros terrenos de igual tamaño, abonóndoles a precio de tasación el valor de los cultivos y el de las construcciones existentes.

4.-Las vías y caídas de agua, lavaderos, minas y yacimientos minerales, incluso carbones, sales de toda especie, piedras de construcción. arenas, cales, pizarras y demás materias de este género que quedarán de propiedad del Estado.

Servidumbres.-Todas las tierras de Montaña están afectadas a las servidumbres generales establecidas en los Códigos Civil, de Aguas y de Minería, y a las de libre tránsito por los puentes, oroyas y caminos públicos que existen y sean construídos dentro de los terrenos concedidos; y a la servidumbre de paso libre de líneas telegráficas, vías de comunicación de toda especie que sea necesario establecer; transmisión de fuerza, irrigación y desaguiue de los fundos adyacentes y la servidumbro que demande su reparación y conservación.

\section{FORMAS DE ADQUTRIR LAS TIERRAS DE MONTAÑA.}

Son cuatro: venta, denuncio, adjudicación gratuita y concesión.Todo peruano o extranjero, en el goce de sus derechos civiles, y toda empresa o sociedad anónima, cualquiera que sea su nacionalidad, tienen derecho para comprar, denunciar o solicitar del Gobiemo la adjudicación, concesión o permiso para exploración de tierras de montaña de propiedad fiscal. (Art. 16 del Reglamento de la Ley).

No pueden adquirir terrenos de montaña directa ni indirectamente so pena de nulidad: El Presidente de la República, el Ministro y el Direc. tor de Fomento, el Jefe y empleados de la Sección Industrias. Tampoco podrón adquirir terrenos de montaña en ninguna forma, en la zona territorial donde ejerzan sus funciones los prefectos, subprefectos, gobernadores, peritos regionales $y$ en general todos los empleados que intervengan en la tramitación de los expedientes.

Es obligatorio para todo aquel que desee adquirir dominio sobre torrenos de montaña, expresar claramente el empleo o explotación a que in. tenta someterlos, quedando bien entendido, que después de concedidos $p a$ ra un uso no podrán ser dedicados a otros, sin onuncio del gobierno, so pena de caducidad de la concesión. (Art. 26 del Reglamento).

Como hemos mencionado anteriormente las formas de adquirir los terrenos de montaña son las siguientes:
1.-Venta;
2.-Denuncio;
3.-Adjudicación gratuita; Y
4.-Concesión. 
Venta.-Por la venta se concede el dominio perpétuo $\mathrm{y}$ absoluto de los terrenos de montaña, a razón de un sol por Ha. (Por Resolución posterior a diez soles por Ha.). No se podrá conceder en venta a una sola persona o compañía una extensión mayor de mil Has. de terrenos o de treinta mil para explotación de la industria gomera; las ventas mayores de treinta mil Has. solo las puede acordar el Congreso.

Si transcurren diez años de la toma de posesión y el propietario del lote no lo ha cultivado y explotado por lo menos en una quinta parte de su extensión, quedará obligado al pago de una contribución anual de un centavo, por cada una de las hectáreas no cultivadas a explotadas. Esto en nuestro concepto es una falla de la ley, puesto que el pago de un cen. tavo es un impuesto irrisorio, mucho mejor hubiera sido que la falta de cultivo acarrease la rescisión del contrato.

Denuncio.-Es el modo de adquirir tierras de montaña para usufructuarlas, pagando una contribución semestral. El canon semestral es de cinco centavos por Ha. $Y$ las personas que dejen transcurrir dos semestres sucesivos sin abonarlo, perderán todo derecho sobre los terrenos que hubiesen adquirido, volviendo éstos al dominio del Estado.

Nadie puede adquirir por concepto de denuncio más de cincuenta mil Has. de tierras de montaña sin previa autorización del Poder Legislativo.

Adjudicación gratuita.-Consiste en la entrega de un lote sin retribución alguna. Los lotes que se adjudican en esta forma no podrán ser mayores de cinco hectáreas. Solo tienen derechơ a pedir estas adjudicaciones gratuitas las personas individuales que reúnan los requisitos establecidos en el Art. 40 del Reglamento, a saber:

a.--Ser reconocidamente pobre; $Y$

b.-Tener establecida su residencia en las tierras pretendidas o en sus inmediaciones, o que declaren su intención de residir en ellas.

Caduca la adjudicación, si tres años después de efectuada no se ha cultivado o explotado, por lo menos la quinta parte del lote cedido, o se comprueba que no exporta sus productos por alguno de los puertos de la República o si no comunica a las autoridades el cambio de cultivo para el que solicitó el lote. Si el adjudicatario abandona la concesión por más de dos años pierde todo derecho sobre el terreno así como sobre los cultivos y capitales fijos que haya introducido.

Concesión.-Consiste en la entrega que hace el Gobierno, de tierras - de montaña para colonizar o en compensación de la construcción de ferrocarriles, caminos y otras obras públicas (art. 46 del Reglamento).

Hay pues dos clases de concesión, una que tiene por objeto la colonización y otra que es una simple cesión de un terreno en pago de la construcción de ferrocarriles, caminos y obras públicas. La valorización que se 
hace en estos casos de los terrenos concedidos es la siguiente: si es para colonización un centaro por $\mathrm{Ha}$. $\mathrm{y}$ si es en compensación de trabajos efectuados un sol por hectárea.

Las concesiones están sujetas en general a las siguientes condiciones que establecen los arts. 49 y 47 del Reglamento de Terrenos de Montafia. Así los terrenos por cederse, cualquiera que sea su ubicación serón divididas en lotes no mayores, de cinco mil Has., separados entre sí por distancias no menores de cinco kilómetros. La finalidad es obvia, con esta medida se trata de evitar el Iatifundio. Establece también la ley entre a tras condiciones que: el tráfico por los caminos y puentes ya establecidos - que en adelante se establecieren, será enteramente libre, no pudiendo el concesionario grabarlo con derecho de peaje, postaje o almacenaje; que será igualmente libre el aprovechamiento de los pastos naturales por las acémilas que trafiquen esos caminos $\mathrm{y}$, el uso de los almacenes o depósitos que se construyan como anexos a ellos.

Todos las prodiuctos que se obtengan en los terrenos concedidos, de berán ser exportados únicamente por los puertos de la República, bajo pena de rescisión del contrato sin responsabilidad de ninguna especie para el Estado $\mathrm{y}$ de pérdida de todos los gastos que se hubiesen hecho en los terrenos. Prescribe además el art. 47 del Reglamento que en ningún caso se cederá terrenos de montaña para colonización si el concesionario no se compromete a cultivar dentro de los primeros diez años de su contrato por lo menos la quinta pärte del terreno cedido, y a pagar a partir del vencimiento del mismo plazo una contribución anual que gravará la parte no cultivada, a razón de un centavo por hectárea.

\section{PROCEDIMIENTO PARA. OBTENER TIEPRAS DE MONTÃ̃̃}

El procedimiento en sí encara dos vías: procedimiento para obtener tierras con la finalidad de explorarlas y procedimiento para explotar las tierras de montaña.

El procedimiento para la exploración es una novedad en nuestra legislación, pues toda persona que desee estudiar o reconocer terrenos de montaña, puede solicitar de la prefectura respectiva el correspondiente permiso de exploración. La solicitud debe ir acompañada de un croquis de la zona que se pretende explorar $y$ del comprobante de pago de haber satisfecho el derecho de diez centavos por hectárea de terreno solicitado; debe precisar además la extensión del terreno en hectóreas, su ubicación aproximada y el río o quebrada en que se encuentra, sin estos requisitos las peticiones se considerarán improcedentes.

En ningún caso, sostiene el art. 57 del Reglamento se concederá permiso perra explorar terrenos que hayan sido objeto de dos exploraciones anteriores.

Los permisos de exploración no pueden exceder de un año de duración ni de treintamil hectáreas. El año de duración principiará a contarse desde la fecha en que se acuerde el permiso. Agrega también el Reglamento de Tierras que, los exploradores de una zona tienen derecho prefe- 
rencial sobre toda otra persona, para comprar o denumciar total o parcialmente el terreno explorado.

Las solicitudes de exploración serán presentadas ante la prefectura respectiva dice el Reglamento, sin embargo este dispositivo ha sido modificado por el Decreto Supremo del 30 de diciembre de 1940 que establece y reglamenta las Delegaciones de Tierras de Montaña, de tal manera pues, que las solicitudes se presentan ante el Delegado de Tierras respectivo, el que las elevará a la Dirección de Fomento con el informe circunstanciado correspondiente si el pedido fuera de más de diể mil Has.: tramitándolas y resolviéndolas, en caso contrario, sin omitir dar cuenta de la resolución final al mismo despacho, dentro de los ocho primeros días de expedida.

Las concesiones de exploración que exceden de diez mil hectáreas sólo serán válidas $\mathrm{Y}$ surtirán efectos legales, cuando hayan sido otorgadas por el Gobierno previo informe del Delegado de Tierras de la circunscripción en que estén situados los terrenos por estudiarse. Cuando la petición de exploración se refiere a extensión menor de diez mil hectóreas, Ia acordará directamente el Delegado.

\section{Tramitación para explorar tierras de Montaña.-}

Las solicitudes de compra, denuncio $y$ adjudicación gratuita se presentan por duplicado $y$ por escrito ante el Delegado de Tierras en cuya jurisdicción se encuentre el terreno que se trata de adquirir o explotar. En la solicitud debe consignarse además el nombre, edad, nacionalidad, profesión y domicilio legal del peticionario, la ubicación y extensión aproximada del terreno con todas las señales que sirvan para distinguirlo, acompañando un croquis respectivo y el nombre de los colindantẹs si los hubiere; debe señalarse también el nombre de la población y el de los ríos o lagunas inmediatas así como la naturaleza de la explotación a que se intente someter el terreno.

Cuando se trata de compra de terreno, el peticionario debe acompañar la constancia de recaudación que acredite haberse erogado el veinte por ciento del valor del terreno.-Si se trata de denuncio debe acompañarse el comprobante que acredite haberse abonado el importe de un semestre de la contribución.

Todos los denuncios se asentarán en el libro de Registro de Presentaciones que funciona en las Delegaciones de Tierras, otorgándose. al peticionario un comprobante de haber extendido el asiento que corresponde $\alpha$ su nombre.

Presentada la solicitud, se ordenará la publicación por treinta días de avisos, que se fijarán en el lugar de acceso más frecuentado por el público, en la prefectura y en la población más inmediata al lugar en que se encuentre el terreno, sin perjuicio de publicarlos también, en el periódico local de más circulación a costa del interesado.

Pasados treinta días de la última publicación, sin haberse deducido oposición, se agrega al expediente un ejemplar de aquella, y se ordenará 
la mensura y alinderamiento y entrega de posesión del terreno por el respectivo perito regional, quien deberá presentar el resultado de sus operaciones dentro de los noventa días siguientes, más el término de la distancia, contados desde la fecha en que le fuera entregado el expediente.

Para el efecto de la mensura $\mathrm{y}$ deslinde, el perito debe trasladarse al terreno, citándose por oficio, con cuatro días de anticipación, a los propietarios codindantes $y$, en ausencia de -stos, a sus apoderados o administradores a fin de iniciar los trabajos. De la operación de mensura y deslinde se extenderá una acta respectiva, que suscribirán el perito, los propietarios colindantes que hubieran asistido y la autoridad del lugar, o dos vecinos notables a falta de ésta. Puede suceder que uno de los colindantes haga observaciones en el sentido de que el señalamiento del terreno invade su propiedad; en este caso la controversia no se resuelve inmediatamente, sino que tiene que ser resuelta por resolución ministerial.

De todo esto, el perito hará un informe de lo más preciso para elevarlo o al Delegado de Tierras o al Ministerio de Fomento, según los casos.

Terminada la operación de mensura y alinderamiento sin haberse formulado oposición alguna se procederó a ministrar la posesión del terreno. La toma de posesión confiere al peticionario el derecho de "tenencia" o de goce del terreno; pero no el de pertenencia que solo se obtendrá mediante el otorgamiento del título definitivo extendido por el Ministerio de Fomento. La toma de posesión se realiza también sentando una acta suscrita por el peticionario o su representante legal, el perito, la autoridad del lugar $y$ dos vecinos notables si éste faltara y también los colindantes que hubieran asistido a las operaciones de mensura y alinderamiento.

De la Oposición.-La oposición es la presentación fundada que se hace ante la cutoridad administrativa competente, con el propósito de impedir la adquisición, por tercera persona, de un derecho que ya ha sido reconocido o que posee otra.

Los escritos de oposición serón recibidos y registrados en la misma forma que las solicitudes de presentación. Las oposiciones pueden producirse en cualquier momento de la tramitación del expediente que las motiva; pero una vez inscritos los terrenos en el Padrón de Tierras de Montaña, sólo podrá disputarse su propiedad ante el Poder Judicial. (Ârt. 102 del Reglamento).

Toda oposición a tenor de lo establecido por el art. 101 del Reglamento, será declarada improcedente si no está fundada en los siguientes documentos:

a.-En el título o en el certificado expedido en conformidad con este Reglamento, $y$ destinado a acreditar que el terreno ha sido concedido o solicitado anteriormente.

b.-En las actas de mensura o posesión.

c.-En el último recibo de la contribución, si la oposición versara sobre denuncio.

d.-En cualquiera de los siguientes títulos legales: 
1.-Los expedidos por el Ministerio de Fomento conforme a la ley del 21 de Diciembre de 1899, registrado en el mismo Ministerio;

2.-Los expedidos por el mismo Despacho a mérito de la ejecución de contratos de colonización o de construcción de caminos o vías férreas;

3.-Las escrituras públicas de compra-venta, permuta, donación, partición o herencia, celebrados antes del 31 de Diciembre de 1909 , siempre que los terrenos materia de ellos hayan sido adquiridos con arreglo a las leyes, y se encuentren inscritos en el Registro de la Propiedad Inmueble.

e.-En el comprobante de haberse concedido o solicitado con anterioridad permiso para explorar la zona sobre la que versa la oposición.

Presentada la oposición fundada en alguno de los títulos enumerados anteriormente, el Delegado procederá a tramitarla dentro del plazo de noventa días, en el que se mandará practicar todos los esclarecimientos necescrios para la resolución más acertada. Vencido el término de noventa días, el expediente será remitido al Ministerio de Fomento para su resolución final.

Declarada infundada la oposición, inmediatamente después de devuelto el expediente a la Delegación de Tierras correspondientes, se ordenará que este siga su tramitación normal, hasta otorgarse el certificado o título de haberse satisfecho todos los requisitos relativos a la adquisición del terreno.

Desde luego que hay que hacer aqui una aclaración, no es lo mismo certificado que título. El certificado es el comprobante que al entregarse confiere temporalmente al peticionario el derecho de simple tenencia o goce del terreno, pero no lo faculta para disponer de él. En cambio el título es el documento definitivo expedido por el Gobiemo y suscrito por el Ministro del Ramo que otorga el derecho de propiedad sobre el terreno.

Es requisito indispensable para recoger el título definitivo, exhibir el certificado de tenencia. Inmediatamente de expedido el título, será inscrito en el Registro respectivo y en el Padrón de Tierras de Montaña, que se llevará en la Sección Industrias del Ministerio de Fomento.

Esta es a grandes rasgos la tramitación de un expediente de Denuncio o Adjudicación de Terrenos de Montaña, nos queda agregar, que todos los que se dediquen a la explotación de terrenos de montaña, estón obligados $\alpha$ exportar sus productos por una de las Aduanas de la República, que previamente haya sido designado ante el Gobiemo; y si así no lo hicieren perderán totalmente sus derechos sobre el terreno adquirido.

Además de las leyes que hemos enunciado hay que considerar también las leyes promulgadas en época del General Benavides expropiando. terrenos de Montaña no cultivados al oriente de la Cordillera de los Andes, para su colonización. Estas leyes son: 8621 del 20 de Enero de 1938 y lar 8687 del $1^{\circ}$ de Julio del mismo año. 
La ley 8621, se promulgó a raíz de la construcción de las carreteras de penetración a las regiones de la montaña $y$ bosques $y$ tuvo por finclidad expropiar los terrenos y bosques no cultivados al oriente de la Cordillera de los Āndes, y, a lo largo de las carretercis recientemente construídas o que se construyan con fondos fiscales y dentro de una faja de cinco kilómetros a ambos lados de la carretera, debiendo dedicarse estos terrenos a la colonización. Establece esta ley que la expropiación de los terrenos se efectuará con sujeción a la Ley 4113 sobre expropiaciones para servicios militares y navales.

Sin embargo no ha llegado a expropiarse la totalidad de los terrenos mencionados, sino sólo el ochenta por ciento de las tierras.

La Ley 8687.--Esta ley se dió con la finalidad de asegurar la tranquilidad y bienestar económico tanto del empleado, como del obrero y campesino peruano. Establece la colonización de terrenos de montaña en las zonas que cruza la autovía Huánuco hacia el río Bajo Ucayali, formando núcleos de colonización, destinados a la pequeña, mediana propiedad a la agricultura extensiva.

La ley en sí no consta sino de tres artículos, sin embargo su finalidad es laudable ya que tiende a proteger al colono peruano y establece una nueva clasificación de las tierras de cultivo.

Para la mejor ejecución de esta ley, se promulgó el Reglamento del Centro de Colonización de Tingo María el 23 de Julio de 1938, en donde en forma clara se establecen los dispositivos concernientes a los colonos, al centro de Colonización y a la división de la propiedad.

Según el art. 3 de este Reglamento los núcleos de Colonización destinados a la Pequeña Propiedad deben establecerse dentro de los dos kiló metros a cada lado del eje de la autovía. Estos lotes no tendrón una extensión mayor de treinta hectáreas y se dividen en lotes de 15 hectáreas para cacia colono de la clase $A$ y $B$ con un fren máximo sobre la autovía de ciento cincuenta metros; y para los colonos de la clase $\mathrm{C}$ en Lotes hasta de treinta hectáreas con un frente máximo hasta de trescientos metros sobre la autovía.

De lo expuesto se desprende que los colonos son clasificados por el Reglamento en clases A, B, C.-Son Colonos de clase A: los peruanos que hayan cursado la instrucción Primaria completa; los licenciados que sean clases de los institutos armados; los obreros y los pequeños agricultores jefes de familia, siempre que por sus condiciones merezcan la protención económica del Estado.

Son colonos de la Clase B: los trabajadores nacionales que constituyan la mano de obra de la Granja de Colonización de Tingo María. Son colonos de la clase C: los nacionales que por disponer de un pequeño capital de Mil soles como mínimun necesiten la protención del Gobiemo para establecerse domo agricultores.

La mira pues, de este Reglamento es la protección al colono nacional y lo hace atendiendo al establecimiento del colono de la peqseña propiodad, proporcionándole gratuitamente. 
a.-Su transporte a la Colonia; b.-Casa habitación; c.-Menaje adecuado; y $\mathrm{d}$.-herramientas y semillas; recibiendo los colonos de la clase A, además racionamiento gratuito para él y su familia durante seis meses a partir de su instalación en la Colonia y una hectórea anticipadamente sembrada con productos tropicales diversos a título gratuito.

Mediana propiedad.-Los lotes destinados para mediana propiedad no tendrón una extensión mayor de cien hectóreas, con un frente máximo hasta de mil metros a un camino de acceso a la autovía.-Podrón ser colonos de la mediana propiedad los peruanos y los extranjeros nacionalizados, quel dando sujeta la admisión de los últimos a juicio del Gobierno.

\section{Propiedad para la explotación agropecuaria extensiva}

Estos núcleos o lotes se adquieren mediante contrato de compro-venta, a plazos, en lotes cuya extensión estará en relación al capital de que disponga el solicitante, no pudiendo exceder de tres mil hectáreas. Estos núcleos se encuentran comprendidos entre el sector del puente sobre el río Tulumayo a la Cordillera Divisoria klm. 197, contados de Pucallpa hacia Huánuco.

La presentación de las solicitudes para ser colonos se hará ante la Dirección de Agricultura, Ganadería y Colonización en el formulario que proporcionan sus dependencias, excepto la del colono que constituya la mano de obra de la Granja de colonización de Tingo María, la que deberák ser presentada ante ese plantel. Las solicitudes deben acompañarse de los certificados de buena salud otorgados por los médicos de la Dirección de Salubridad adscritos para ese efecto a la Dirección de Agricultura, Ganadería y Colonización.

Pagos de los derechos.-Los colonos de pequeño capital, pagarán el valor de su lote en un plazo de viente años, en armadas anuales y a partir del tercer año de su instalación.

Los trabajadores que constituyan la mano de obra de la Granja de Colonización de Tingo María, pagarán el valor de sus lotes con jornales anuales equivalentes a la veinteava de su valor. Los colonos de la mediana propiedad pagarón el valor del lote de la manera siguiente: el $10 \%$ (Diez por ciento) al firmarse el contrato y el saldo en diez anualidades que se harón efectivas dentro del primer trimestre de cada año.

Para el caso del colono de propiedad para la explotación Agropecuaria Extensiva, éste deberá pagar el valor de los terrenos en diez años y de la siguiente forma: el veinte por ciento como cuota inicial y el saldo en diez anualidades que abonará adelantadas dentro del primer trimestre de cada año.

El precio de los terrenos, sostiene el art. 45 (Del Reglamento del Centro de Colonización de Tingo María) estará en relación con la valorización de los terrenos, clasificándose éstos en tres categorías: Primera, Se- 
gunda y Tercera, atendiendo a su naturaleza, topografía, posibilidad de riego, proximidad al eje de la autovía y su cercanía a los centros poblados, ríos, quebradas o saltos de agua. Por ningún motivo el precio del valor del terreno debe ser menor de diez soles, ni mayor de cincuenta soles la hectórea.

Este Reglamento pues ha sido elaborado con un. criterio mós técnico, si lo comparamos con la ley 1220 y su respectiva Reglamentación que no hacía discriminación alguna respecto de los terrenos de montaña.

\section{REGIMEN DE LAS TIERRAS DE BOSQUES}

Es importante tratar también del régimen de las tierras de bosques. por cuanto constituyen estos una fuente de riqueza nacional. La legislación en cuanto a esta materia es la misma que rige para las tierras de montaña. En efecto el art. 24 de la Ley 1220 remite la reglamentación al Gobierno, imponiéndole el considerar especialmente el procedimiento para la explo. fación de los bosques y árboles de goma, en forma tal que se prohiba eficazmente la destrucción de un árbol, sin la plantación de su reemplazo. Pero es en el Reglamento del 11 de marzo de 1910 en donde se establece las reglas especiales respecto a la explotación del caucho y las maderas. Sin embargo es lamentable, que este Reglomento haya omitido hacer una clasificación de las diversas especies de árboles, (tales como los de construcción o ebanistería; usos industriales y usos farmacéuticos), para reglamentar debidamente la explotación de cada clase. El Reglamento solo se refiere al caucho y a la explotación de maderas.

Establece así el art. 188 del Reglamento que todos los que obtengan terrenos de montaña para la explotación de árboles de caucho, podrán beneficiar éstos en la forma que mejor convenga a sus intereses; pera quedan expresamente obligados a sembrar y cuidar por lo menos, cincol plantas del mismo vegetal por cada árbol que se destruyan.

La extracción del jebe o shiringa debe hacerse teniendo en cuentá sobre todo la conservación de los árboles; siendo prohibida la destrucción: de estos, so pretexto de extraer mayor cantidad de latex. Los que infrinjan esta disposición están obligados a plantar cinco árboles por cada uno dé los que destruyan, sin perjuicio de pagar una multa de doscientos soles (S/. 200.00).

Respecto a las incisiones no deben hacerse a menos de cuarenta centímetros del suelo ni a más de dos metros sobre el nivel del mismo, teniendo en cuenta el tamaño del árbol; tampoco deben ser tan profundas que penetren hasta el tronco. Al hacerse las incisiones debe cuidarse de no lastimar la cáscara y de que no sean muy largas, evitando agujerear inútilmente los árboles. Los cortes deben hacerse transversal $\mathbf{u}$ oblicuamente y sólo hasta la tercera parte del tronco. Por ningún motivo podrá hacerse más de doce cortes en cada árbol, según el tamaño y la robustez que tengan, debiendo existir un intervalo entre corte y corte de sesen- 
ta horas. Terminada la extracción del latex deben cubrirse las incisiones con cera o barro y dejarse descanstar al krbol por to menos durante seis meses.

En cuanto a la explotación de maderas, sólo será permitido el corte de los árboles que hayan llegado a su completo desarrollo o dado semilla abundante; quedando prohibido, en absoluto, derribar árboles tiernos - renuevos que puedán servir para la repoblación de los bosques. Lo mismo que en el caso del caucho, por cada árbol que se beneficie para el aprovechamiento de su madera, será obligatorio sembrar y cuidar cinco árboles que puedan destinarse al mismo objeto, o bien de caucho o shiringa.

La falta de cumplimiento de las anteriores disposiciones producirá la caducidad del contrato después del segundo año de la toma de posesión, con pérdida, para el adjudicatario del terreno, de los capitales fijos y del depósito que establece el art. 198 del Reglamento. Según este artículo, para obtener certificado de pasesión de terrenos que van a dedicarse a la explotación de gomas, maderas, resinas, cortezas, etc, es condición esencial, además de los requisitos establecidos por este Reglamento, oblar en la Caja de Depósitos y Consignaciones, la suma de un sol por hectárea, $\alpha$ fin de garantizar el cumplimiento de las anteriores disposiciones.

Para controlar el cumplimiento de las disposiciones referentes al caucho $y$ explotación de maderas, el perito regional o su sustituto deberá visitar anualmente todos los fundos comprendidos en su jurisdicción, dando cuenta detallada del número y estado de las plantas cultivadas en cada fundo.

\section{El DENUNCIO TEMPORAL DE LAS PLAYAS DE LOS RIOS}

Es interesante también anotar cómo se ha reglamentado el otorgamiento de certiticados de posesión para uso temporal de las playas de los ríos de nuestrá selva, así como las que existán en las márgenes de los lagos e islas de la Región de Oriente. A este respecto debemos mencionar que esta reglamentación ha obedecido exclusivamente a la mayor obtención de productos alimenticios, aprovechando las playas en época de vaciante, tratando sobre todo de estimular al agricultor de la selva. El Decreto Supremo del 8 de abril de 1953 y la Resolución Ministerial del 30 de mayo de 1953 reglamentan los denuncios a este respecto.

Se considera como playa, las fajas de tierras sin bosques y que quedan en seco durante la época de vaciante de las aguas. Las solicitudes para la utilización temporal de las playas serón presentadas por los interesados en las dependencias del Ministerio de Agricultura de la jurisdicción. En dichas solicitudes se consignará el nombre y dirección del solicitante; número de hectáreas $\mathrm{y}$ objeto $\alpha$ que se destinarán; playa en que se solicitan y su ubicación, acompañando un croquis del lugar.

Estas solicitudes se presentarán desde el $1^{\circ}$ de Enero hasta el 31 
de Julio de cada año, si se trata de aprovechamiento agrícola, y durante todo el año si es para pastoreo. Las solicitudes en que se indique que el empleo de las playas será para el sembrío de artículos alimenticios tendrá prioridad sobre cualquiera otra utilización. Los certificados de posesión serán anuales y renovables, con derecho de prioridad para los concesionarios anteriores.

Las dependencias del Ministerio de Agricultura (Servicios Regionales, Centros Agropecuarios y de Colonización y Delegaciones de Tierras. de Montaña), están autorizados para otorgar certificados de posesión hasia por 50 hectóreas. Estos certificados son intransferibles, no pudiendo los concesionarios establecer en los lotes otorgados arrendatarios ni partidarios.

Los peticionarios que reciban certificados de posesión, estón obligados a cultivar cuando menos el setenticinco (75\%) por ciento del área aprovechable, debiendo abonar por cada hectárea dejada de sembrar sobre el porcentaje señalado, la suma de veinte soles por concepto de multa, en la Caja de Depósitos y Consignaciones (Cuenta Fondos de Colonización del Oriente).-Los ocupantes clandestinos de playas abonarán por hectárea ocupada la suma de veinte soles, también en la Caja de Depósitos y Consignaciones.

Sólo se concederó autorización para el pastoreo de animales en las playas no solicitadas para fines agrícolas. Sin embargo, si la extensión libre de una playa lo permitiera, podrá ser autorizado el pastoreo en parte de ella, si el beneficiado asegura el cercado de su concesión y se responsabiliza por los daños que su ganado pudiera ocasionar en los sembríos vecinos.

Establece también el Decreto Supremo del 8 de abril de 1953 que los Ceríficados de Posesión otorgados por el Ministerio de Ágricultura, seróm considerados por el Banco de Fomento Agropecuario del Perú, para el otorgamiento de "Préstamos de pequeña Agricultura, en la forma que establece su Ley y Estatutos. 